\title{
Information technology and interests in scholarly communication: a discourse analysis
}

Neil Jacobs, Loughborough University, LOUGHBOROUGH, Leicestershire, LE11 3TU, Great Britain.

n.a.jacobs@,lboro.ac.uk

\section{Abstract}

Although technological determinism is an inadequate description of change, it remains common, if implicit, in much information science literature. Recent developments in science and technology studies offer a social constructivist alternative, in which technology is seen, not as autonomous, but as the result of interests. However, the stability of these interests can be argued to privilege social factors in the same way as technological determinism privileges technological factors. A second alternative is to shift to a relativist stance and analyse discourse as interaction, rather than as a neutral carrier of information, or communication. The focus of the discourse analyses of interview interactions presented in this paper is on two aspects of discursive structure, the indexical category of 'research', and interest management, which refers to the ways that participants manage their own and others' stakes in particular accounts. The paper concludes by noting how formal scholarly communication acts as a 'category entitlement' in interviews, and how technological determinism works as a dilemma for this entitlement that participants (including researchers) negotiate at the very local level of their interactions and accounts. 


\section{Introduction}

In whose interests is information technology? Borgman (2000) notes that "the circumstances of scholarly communication are changing as a result of advances in telecommunications, the advent of computer networks and the World Wide Web, the availability of digital libraries and the transition from print to electronic publishing" (Borgman, 2000, p.413). Several writers have considered how this might affect practices and institutions related to scholarly communication (Day et al, 1993; Costa and Meadows, 2000; McKnight et al, 2000). However, there have perhaps been two features of such research that are open to criticism. Firstly, such research often considers scholarly communication to consist solely of artefacts, such as journals and citations, rather than these being particular manifestations of more subtle processes. Secondly, there has been a tendency to view technology as relatively autonomous, using a model wherein social, economic or professional matters are somehow a dependent variable, reacting to changes in technology. To address the initial question with reference to scholarly communication as a whole requires that it be placed, at least provisionally, in a theoretical framework in which neither technology nor scholarly communication are understood as stable, uncontested phenomena. This paper seeks to sketch an outline (with examples) of what one such approach might look like. It starts by briefly reviewing notions of technology and of scholarly communication, before shifting the focus to discourse and to how such notions are articulated in three examples taken from interviews with a researcher, a librarian and a document supplier. 


\section{Technology and interests}

Theories of technology are legion. Some, such as that of Heidegger (1977) posit some essential and timeless quality to technology although, paradoxically perhaps, this does not preclude the possibility of radical discontinuity. Less profound versions of technological determinism exist, such as those that inform dystopian and utopian texts concerned with the coming of the 'information age'. Several theoretical stances have configured themselves against this view of technology (Williams and Edge, 1992, 1996), including at least four distinct research traditions in the social sciences: economic analyses of technological change; critical studies of technology policy; the sociology of industrial organisations; and the social construction of technology (SCOT). Of these, economic and policy analyses of technology see the artefact as stable, and neo-Marxist approaches such as the sociology of industrial organisations see the interests of actors as stable, but SCOT approaches emphasise the instability and constructed nature of both technological artefacts and interests.

SCOT was developed as an analytic approach owing much to previous work in science studies, particularly that undertaken by Collins $(1981,1998)$. In this work, the content of scientific knowledge was subject to sociological analysis according to the "empirical programme of relativism', in which results from experiments were understood as not selfevidencing, allowing for a certain interpretative flexibility, which was then closed down by social and rhetorical moves associated with identifiable 'interests' until the facts were established. Although doing some violence to the subtlety of Collins' approach, this description serves to illustrate the similarities with SCOT. SCOT approaches are 
exemplified perhaps by the detailed work of Bijker (1995), the ambitious surveys of Hughes (1983), and the reflexive studies of Grint and Woolgar (1997). Classic SCOT work such as that of Pinch and Bijker (1987) follows closely the empirical programme of relativism, showing how the form of what would emerge as a recognisable artefact was initially not clear (interpretative flexibility), and how the interests of relevant social groups caused that form to converge into a single version.

The social constructivist approach to technology has been criticised on a number of grounds, the principal one being that the approach privileges social factors in the same way that other approaches (Davenport, 1993; Ekman and Quandt, 1999; Warner, 2000) privilege economic factors. Woolgar (1981) in particular has noted that explanations based on 'interests' tend to infer the existence and character of those interests from the very phenomena that they are recruited to explain. Suggesting that this kind of bootstrapping may be ubiquitous in sociological accounts, Woolgar (1988) seems to favour textual reflexivity (or persistent deconstruction) as one way of incorporating the critique into sociological accounts. While acknowledging this as one response, it is also possible to shift the analytic gaze onto accounts other than sociological ones, taking interests as topic rather than, as in social constructivism, as explanatory resource in accounts concerning technology.

\section{Scholarly communication and the indexical turn}


Meadows (1998) has noted that "For efficient communication of research information, formal printed sources must be complemented by informal (usually oral) sources" (Meadows, 1998, p.133). However, such an inclusive approach is not always evident in information science research. Certainly, scientometric approaches (Kelland and Young, 1998; Jacobs, Woodfield and Morris, 2000) usually exclude informal communication because it is not generally susceptible to summary as quantitative data (MacRoberts and MacRoberts, 1996). Qualitative approaches offer the possibility of a more inclusive approach, especially if a reflexive, ethnomethodological (Garfinkel, 1967; Crabtree et al, 2000) perspective informs the analysis. Such a perspective assumes that all action, including that associated with research, is indexical, that is, it is concerned with the practical conduct of the interaction at hand. This is relevant to both formal (Woolgar, 1991) and informal (Pollner, forthcoming) features of communication, and furthermore it constitutes the research fieldwork itself as such an interaction, rather than as an information gathering exercise. Scholarly communication, then, includes not only journals, citations, informal networks and so on, but also the meta-communication that takes place as research into such events. (The type of infinite regress possible here is addressed by Ashmore (1989).)

\section{Discourse}

The discussions above have pointed to the need for an analytic focus that is concerned both with the mutual construction of technology and interests, and with scholarly communication as an indexical phenomenon. One methodological approach that might answer these needs would be a form of discourse analysis that sought to synthesise 
insights from post-structuralism (Foucault, 1972; Parker, 1992; Frohmann, 1994; Doolin, 1998; Kerslake and O'Brien, 1999) and ethnomethodological conversation analysis (Sacks, 1992; Schegloff, 1992; Psathas, 1995). While the post-structuralist perspective has been documented in information science (Frohmann, 1994; Budd and Raber, 1996), conversation analysis may be less familiar. It focuses on the fine detail of interactive talk, noting turn-taking and sequential patterns in an effort to develop a persuasive account of why a specific utterance occurred where it did. Highly empirical, even antitheoretical, conversation analysis offers a somewhat problematic partner for poststructuralism. However, a synthesis has been attempted and is described in a programmatic text by Potter and Wetherell (1987). While tensions remain within the approach (Potter (1996) has more recently moved toward a more conversation analytic stance), it remains a fruitful site for research (McKinlay and Potter, 1987; Leudar and Antaki, 1996; Wetherell, 1998; Antaki and Wetherell, 1999). In particular, this approach offers a way of focusing on indexical matters of 'interest' that can be used to explore how both technology and scholarly communication are deployed as lexical and semantic resources in interview interactions.

\section{Indexical matters of 'interest' in interviews concerned with 'technology'}

Interests explanations have been common in social science (for example, as described above in relation to SCOT), where they account for practices by reference to the material, psychological or social interests (or stake) of relevant actors. This type of explanation is the topic, rather than the resource, in discursive approaches. That is, from the discourse 
analytic perspective the focus is on occasions when participants understand each other as invoking interests in the support or challenging of accounts. For example, Antaki and Horowitz (2000) show how one speaker was characterised by a second as having an interest in the story being told by the latter, and this characterisation was heard by both parties as challenging the rights of the first speaker to hear the story in a particular way. Generally, being understood to have an extra-discursive stake in a particular account will undermine one's 'category entitlement' (Potter, 1996), since the stake will be understood as an 'ulterior motive'. Furthermore, participants in interactive talk may make efforts to structure their utterances to make such an inference unavailable on those occasions when it might arise.

Issues of discursive interest management arise where categories of person or activity are made relevant to an account. The notion of 'category entitlement' derives from the work of Sacks (1992) on 'Membership Categorization Devices', which are understood to be formal structures of intelligibility in accounts. Attributing membership of a category to someone (including oneself) necessarily imputes them with characteristics, such as access to specific types of knowledge, that can act as an entitlement (or even an obligation) to offer particular kinds of account in circumstances where that category is relevant. Category-based interest management, then, is a key perspective on how accounts are made and heard.

The analysis of interest management is a powerful analytic perspective, and can be argued to be the general case of many other discursive features. For example, Gilbert and 
Mulkay (1984) describe two 'interpretative repertoires' used by scientists; an 'empirical' repertoire to account for science they saw as correct, and a 'contingent' repertoire to account for what they saw as scientific error. Whereas Potter and Wetherell (1987) include interpretative repertoires in their synthesis, Potter (1996) explains them in terms of interest management, so that scientists discounted the possibility that they may have had an interest in putting forward a certain account by describing the account as inevitable given the data. However, when they were accounting for (what they saw as) scientific error, they invoked the social and psychological interests of the scientists involved. These differential accounting strategies can be argued to be fulfilling two criteria. Firstly, they maintain the category entitlement of the speaker. That is, the status of the speaker as a competent member of the relevant category (scientist) was preserved. This membership is similar in some respects to a 'subject position' in post-structuralist theory. Secondly, they preserved the integrity of the category itself (science), since error was described by reference to deviation from procedures appropriate to the category, not to problems with those procedures. The ethnomethodological perspective suggests a third criterion fulfilled by the scientists' accounts. The accounts were occasioned, that is, they were part of an interaction (for example, a research interview) and were offered as a part of that interaction (for example, as answers to questions). Thus, the third criterion fulfilled by the scientists' accounts was that they were adequate turns in the interaction of which they formed a part. Whereas any judgement on the first two criteria must refer to the properties of the categories involved, that on the third must refer to indexical features of the interaction as it was conducted at the time. We might generalise the three criteria to be fulfilled by an account offered in a research interview as follows: 
1. The account should ensure that the speaker retains membership of a category that entitles the speaker to offer such an account, otherwise the speaker may be open to a challenge that the account is 'interested';

2. The account should preserve the integrity of the category of which the speaker claims membership for the purposes of the account;

3. The account should be an adequate answer to the interview question, that is, it should be prompted by a question and received as an answer.

These criteria clarify how technology and scholarly communication might occur as resources in an interview. Scholarly communication would seem to be closely related to scientists' discourse, as discussed by Gilbert and Mulkay (1984). Thus, we might expect it to be involved in indexical interest management features of any interview interaction, where it might imply a category ('scholar' or 'competent academic researcher') that is relevant to particular persons. Such a category may be a useful resource in negotiating matters of 'interest'. We might imagine at least two ways in which this resource could be used. Firstly, the category could be made relevant to the interviewee. This would imply that the interviewee was speaking 'as a scholar', and had interests appropriate to this category. This would oblige the interviewee both to protect her/his membership of the category and to sustain the integrity of the category itself. Furthermore, this work would need to be done in a turn that counted as 'an answer' in an interview interaction. Secondly, the category of 'scholar' could be made relevant to persons other than the interviewee. This would effectively enrol the category entitlements and interests of legitimate others into the account being offered. That is, where speakers claimed to 
speak for others not present, then they would be claiming their own 'category entitlement', or membership of a class of persons who had privileged access to certain kinds of information (in this case, the interests of others). Furthermore, such enrolment would offer a picture of the interests of the speaker that excluded any personal stake that could be used to undermine the account. Hence, any interests-based challenge to the account would have plenty of work to do in unpacking its interest management work.

Common approaches to technology, as discussed above, include technological determinism and technology being the result of social or other interests (SCOT). Such approaches are the topic of discourse analysis. Technological determinist accounts allow that technological artifacts have an effect or impact on other matters, such as social organisation. This kind of account is what might be called a 'bottom-line realist' explanation (Edwards, Ashmore and Potter, 1996). It undermines the integrity of the kinds of category discussed above, since does not allow for the obligations and entitlements that are associated with them. For example, if an interview question implies that technology has an effect on the research of interviewees who rely on membership of the category 'researcher' to answer questions in that interview, then we can expect that the interviewees will address themselves to this as a problem in their answers. Analysis 1, below, presents an example of an interview interaction of this kind. On the other hand, if an interview question implies that technology has an effect on some category, and interviewees are asked to select which category, then we can expect them to select a category other than the one they are using for themselves in the interview. Analyses 2 and 3 , below, present examples of this kind. Of course, in both cases another response to 
such questions would be to reject the implicit technological determinism and to reconfigure technology as being the result of category interests, rather than being their cause. However, this response would require much discursive work if it were to result in an account that was taken as an answer to the interview question.

\section{Fieldwork}

A series of semi-structured interviews was undertaken with academic researchers, librarians, and representatives of document suppliers, database aggregators and publishers, as a part of the UK FIDDO Project investigating document delivery options (Jacobs et al, 2000). These interviews offered extensive opportunities for discourse relating to scholarly communication, technology and interests. They were transcribed verbatim, although not according to the full transcription conventions of conversation analysis (Psathas and Anderson, 1990). They are used here as case studies in which participants were engaged in interactive talk wherein their occasioned category membership was likely to be relevant to questions of technology and scholarly communication.

It may be argued that interview data is not appropriate for analysis using discourse analytic methods. Generally, discourse analysis emphasises the use of 'naturally occurring' interactive talk. However, as Edwards (1997, p.89) points out, "while this seems to rule out studies that use experimental procedures or interviews, it does not strictly do so. Any interactional phenomena can be naturalised by treating it as natural. 
So if what you have are interview data, then that is how to treat them, as a species of talkin-interaction, as 'interview', rather than as treating the questioner as researcher, the question schedule as 'method', and only the responses as 'data". This is the approach taken here. Given this approach, each respondent begins the interview as a member of at least two categories, 'interviewee' and, for example, 'academic researcher'. That is, there are certain rules according to which an interviewee generally offers answers to questions, supporting them with accounts and so on. There are also certain ways in which the interviewee's extra-discursive identity, for example as a researcher, acts as a necessary category entitlement for the accounts offered. This duality offers analytic purchase to the interviewer, which was exploited.

Presented below are three excerpts from the interviews, one with an academic researcher, one with an academic librarian, and one with a manager at a major document supply organisation. The author was the interviewer in each case. Each excerpt is analysed with reference to its sequential order, with a focus on interest management issues resulting from category memberships and explanations invoking technology, as discussed above.

The matter of what constitutes the relevant context for the following excerpts is not straightforward. Practitioners of conversation analysis claim that the only relevant context for any utterance is that to which the utterer demonstrably orients in that utterance (Schegloff, 1997). However, it may be reasonable to offer further information, including the interview schedules, and these can be found in the Appendix, as well as in a published description of the FIDDO work (Jacobs et al, 2000). 


\section{Analysis 1: the academic researcher and the interviewer}

[1] Interviewer: So do you think overall having access to Searchbank is going to have an effect on how much or the quality of your research

[2] Respondent: Yes it's going to save me time and leave more time available for fieldwork, interviewing and so on There is so much stuff published that the more efficient and faster the searches can be done for you and the more easily you can retrieve the bits you want you get a bigger overview obviously in the first place of the literature and you pick what you want from it more quickly and then you can go and get on with the fieldwork side of it

[10] Interviewer: $\mathrm{Ok}$ which you see as the real research bit

[12] Respondent: Well yes I do Research is finding out something about the world And this idea of re-jigging what other people have written before and lashing it together into a different mixture I mean a lot of people do this and call it research 
[16] Interviewer: You're not convinced

[17] Respondent: I do publish stuff like that I do write stuff like that and that's fair enough I do text books I've written two text books and I'm writing another one I don't call it research but the techniques I use the models and all the rest of it are of a high academic level and it's a very similar process I do when I am writing a research study

[27] Interviewer: Did you have any technical issues when using Searchbank

In utterance [1], the interviewer asks whether a particular technological solution, in this case a Web-based, full-text database, will have an effect on the respondent's research. This question was designed to bring into play the kind of category and interest concerns described above. That is, an affirmative answer (as offered here) suggests a position of technological determinism which is highly problematic for the integrity of the category 'research', and hence for the speaker as a member of that category. Researchers have an interest in drawing a boundary around what they do as research to protect their category entitlement, but interviewees have an interest in accounting for answers. Of course, the respondent could have answered negatively, but another interest dilemma could follow 
from that. In utterance [3] the respondent begins his account by equating 'research' with 'time' as the focus of the account. Utterances [4]-[6] hold the key to how an account is constructed to answer the technologically deterministic interview question and support the response in [2], while preserving the category of 'research', and the respondent's membership of that category. Firstly, in utterance [4], the respondent draws a boundary around certain research practices that are not affected by access to Searchbank. The 'researcher' category now protected, he secondly, in utterance [5], notes how certain other practices can be automated; 'the searches can be done for you'. Thirdly, in utterances [6]-[7], he shows how this directly affects what might be called, after the boundary work of utterance [4], 'pre-research' practices ('retrieve bits', 'get a bigger overview'). Note, however, that the practices that are automated are constructed as only ambiguously related to the speaker as a researcher; 'searches' in [5] could just as easily be a library practice. This way of addressing technological determinism, wherein it is not disputed but used as an explanatory resource, allows the respondent to protect his category membership and subject position by showing how it is other positions (here, perhaps the library) that are at risk of automation. By making 'fieldwork' the membership criterion for the category 'research', technology can be described as enabling.

However, the boundary work of utterance [4] has unforeseen consequences. In utterances [10]-[11] and again in [16], the interviewer does not accept the account so far as an adequate answer, but queries the implicit hierarchy constructed by that boundary work. Literature-based work is 're-jigging' (utterance [14]), which the respondent has defined 
outside 'real research'. There is clearly a potential for this account to be heard as rather self-interested, since those engaged in literature search and review are excluded for the purposes of the account at hand. The remainder of the excerpt, from utterance [17] onward, does not constitute an answer to the interview question but is an account of the boundary work that was a part of the answer offered earlier. In this account, the respondent does much discursive work (see, for example, utterances [17]-[21]) to construct another category of which both he and others earlier excluded from 'research' are members. In this account, which is not an answer to the technologically determinist interview question, technology is reconfigured as 'techniques' in utterance [23]. This account of technology as the outcome of scholarly interests mirrors SCOT approaches to explanation.

The above analysis is highly abbreviated, but it shows the lengths to which an respondent has to go to police the category 'research', to limit the inferences available from its use and to make it thereby available to differentiate work that is susceptible to automation from that which is not. The result is a complex discursive construction of the world of scholarly communication and research in which at least three different types of activity are described:

- literature-based activities that can be made efficient and faster and even 'done for you' [5];

- literature review and writing text books, work that is 'of a high academic level' [24];

- research, which 'implies you finding out something new' [26]. 
This complex boundary management is directly traceable to and results from an attempt to resolve the interest dilemma in the interview question. This dilemma, in turn, is based on the notion that category memberships and their associated entitlements have to be configured to work within the technological determinism of the question, unless the interviewee is to reject the terms of the interview question. However, the indexical category of 'interviewee' carries with it an obligation to answer the interview question, and it is not until utterance [27] that the interviewer signals his receipt of an answer, by a unilateral change in topic. It is only in relation both to the lack of any such receipt at utterance [11] or at utterance [16], and to the boundary management work in the earlier part of the excerpt, that it is possible to understand the account in the latter half as relevant. In his attempts to render an adequate answer to the interview question while maintaining his membership of a category 'researcher', the respondent offers a criterion for this membership that itself requires an account. This secondary account uses technology as a dependent, rather than a determining, factor. Technology, although not explicitly named in the excerpt, is therefore key to understanding the way the interaction developed.

\section{Analysis 2: the academic librarian and the interviewer}

The interview question suggested by the respondent in utterance [1] relates to a webbased, full-text database, much like that discussed by the researcher above. The interview schedule (available to both parties throughout the interview and shown in the Appendix) offers a question asking who will win or lose in these circumstances, 
compared to journals on the shelf, and as prompts offers 'publishers, suppliers, libraries, researchers, students'. Again, then, the interview question is firmly patterned as technologically determinist.

[1] Respondent: Compared to Journals on Shelf If the publishers have been compensated then they're not going to lose The suppliers Well Swets and Blackwells seem to be trying to carve out a nice little niche for themselves I'm not convinced they will Libraries I suppose there's always the concern that people will stop physically coming into the library when you can access it all from outside We had this problem a couple of years ago when we noted a pattern of declining usage of the library And as part of my role in the library I had to investigate that and there's no one solution sadly If only there was something you could spot and fix but it's a pattern and it's happening elsewhere but certainly electronic access is part of it I've got a lovely quote from someone at Harvard University who 
says 'the library is the most important building I never go into' Because they don't need to they can do it all from their desktop But that's an ongoing concern to us I would hope the researchers would win on this one Students if they're permitted access can win but again they may need assistance in selecting...

As with the previous excerpt, there is much more going on here than can be described in the space available, so that the analysis is limited to that essential for a focus on technology and scholarly communication.

There are analogous interest management issues in the interviews with librarians as were demonstrated above with respect to researchers. That is, the interview question is phrased in terms of technological determinism (social and economic outcomes depend on technological arrangements) and the respondent, as an interviewee, is expected to offer an account of any answer given, but one that does not threaten her membership of a category of 'librarian'. As we shall see, membership of this category involves significant entitlements to enrol the interests of certain groups, and not others, in support of accounts.

Publishers and suppliers fall into the set of those for whom the respondent as a librarian is not accountable, and whose interests lie outside her scope. Nevertheless, as an 
interviewee she is expected to offer an account, which is given in utterances [2]-[5]. The respondent demonstrates that these interests are excluded from the set of those for which she can speak in the following ways. Firstly, she uses an unelaborated conditional in [2], and this ensures that this account is incomplete, so that she has demonstrated her unaccountability as an interviewee on this subject. Secondly, she invokes a separate 'eyewitness' entitlement ('seem') in [4], which distances this account from her entitlement as a member of the category 'librarian'. That is, she is not offering the account in [4] as a librarian, but as someone who is seeing what 'Swets and Blackwells' are doing, so that she has demonstrated her unaccountability as a librarian on this subject. The respondent, therefore, begins her answer to the interview question by explicitly excluding certain aspects of formal scholarly communication from the set of things that she can account for. These aspects are those concerned with commercial entities, that is, entities whose interests are defined in the interview in terms of market relations.

Following the offered interview structure, the respondent in [6] moves on to consider libraries, for which she obviously is accountable in the interview. The account begins in utterance [7] with 'I suppose', and it may be worth asking why. 'I suppose' can be argued to be a concession marker, that is, as configuring what follows as a concession. Certainly, it works to undermine any hearing of the following proposition in [7] as congruent with the kind of account that would support the speaker's membership of a category of 'librarian', and this is confirmed in [8] when the proposition is described as a 'problem'. This is not a problem with her membership of the category but with the integrity of the category (the second criterion for an interview account to fulfill, as 
described above), and this is signalled by the respondent's switch to 'we' in the account in utterance [8]. This account relates decreasing use of the physical library to 'electronic access' (that is, to technology), and the respondent confirms her position as being unproblematically a member of a problematic category in utterance [9] when she demonstrates having addressed the problem in her capacity as a librarian. This account is not, then, fulfilling one of the three criteria set out above for the completion of successful answers to interview questions. Just as in the excerpt analysed above, the respondent's initial account has caused problems with her interest and entitlement management that she has to address in the second part of her answer, in order that it be an adequate answer. This second account begins in utterance [10], where the category problem is geographically broadened but remains within the technologically determinist pattern. In utterance [11] there is an explicit enrolment of users' interests in legitimating the library role, and this can be contrasted with, for example, utterance [4] where commercial interests are demonstrated to be outside the accountability of a librarian. What is happening, then, is that the interests of users (as 'researchers'), which are resources available to maintain the integrity of the category 'librarian' from which the respondent needs to speak, are disappearing from that category and are instead legitimating technology. Working at networked computers in their offices across campus, users cannot so easily be recruited in discursive support of the library. If changing interests of users are one outcome of a determining technology, then the respondent is left only with 'concern' [14] for the category of 'librarian' and 'hope' [15] for the interests of researchers that are disappearing from that category. We can see, then, that in not challenging the technological determinism of the interview question (as did the 
researcher in the first excerpt), the respondent cannot easily protect her category entitlement to account in the interview from membership of a category 'librarian'.

\section{Analysis 3: the manager at a document supplier and the interviewer}

The following excerpt comes from an interview with a manager at a document supply organisation. This interview followed the same schedule as that from which the second except was taken (see Appendix). The excerpt comes from a very similar place in the interview to that analysed above. Again, it refers to a full-text, web-based database, implying that certain outcomes might result from this technology.

[1] Respondent: ... The library; win or lose.

[2] Is this financial or power?

[3] Interviewer: Just generally speaking.

[4] Whatever librarians are interested in.

[5] Respondent: I mean again, I would have thought libraries, paradoxically...

[6] They lose in one way

[7] they cease to have direct control over what people are reading if it is not immediately available to the researcher on the shelf because the researcher is getting it all through this database. But nonetheless the library's got more power in terms of what I said earlier 
negotiating the contract, monitoring the contract, choosing more contracts, deciding what goes into the database, deciding how you allocate money between the database and material on the shelf. I can't see the libraries losing in any way. Researchers is, I think, a question with only a complex answer to it...

In utterance [1], the respondent reads the relevant part of the interview schedule. In utterance [2], he directly addresses what are to count as the library's interests, the two options offered being financial and power. We have seen in the second excerpt how a respondent can demonstrate membership of a particular category by defining the kinds of interests for which he can account. Certainly, the interviewer seems to recognise utterance [2] as a legitimate question, and he makes two attempts to provide an answer, neither of which explicitly challenge the options given in [2]. The first attempts to broaden the topic from the two options offered by the respondent. The second is an explicit call for the respondent to speak for librarians. Of course, the respondent is not being interviewed as a 'librarian', so that this call is likely (and can be shown) to have particular consequences in the interaction. The respondent introduces his response to this call in an incomplete sentence, utterance [5], which sets up what is to follow in at least three ways. Firstly, in 'I mean again', the speaker makes an explicit link to previous speech turns, implying that what he is about to say is consistent with, and even repeats, what he has said earlier. This can be heard as the respondent taking utterances [3]-[4] as licensing his initial characterisation of libraries' interests as being either financial or 
concerned with power and thus as consistent with the way in which he has worked up his membership of the category 'document supplier' in a previous part of the interview. That the respondent explicitly includes this kind of interest within his accountability (unlike the librarian in the second excerpt), means that they are available as a resource and are used later in the excerpt. Secondly, in 'I would have thought libraries', the respondent hedges what is to come. Having just referred to his category entitlement and interests as a document supplier, the respondent cannot easily speak as a librarian. This framing of utterances [6]-[10] is recalled in [11], which closes the topic of libraries' interests by, among other things, recalling that the previous talk has required a specific 'eyewitness' category entitlement ('I can't see'). The third way in which utterances [6]-[10] are set up in [5] is by 'paradoxically...'. This word does much discursive work. It anticipates that the speaker is about to describe contrasting versions of events or circumstances, but asserts that this contrast is benign and is not easily challengeable on grounds of logical contradiction.

The contrastive pair anticipated in [5] is explicitly signalled in [6] and [8] by the use in [6] of 'in one way' followed in [8] by 'nonetheless'. Utterance [6] mirrors the category problem analysed in the second excerpt, above, wherein the integrity of the category 'librarian' is eroded by the disappearance of users' interests. Again, this is down to adopting the technologically deterministic position from the interview question, wherein technology is invoked as an explanatory resource. However, unlike the librarian in the second excerpt, the respondent here has included financial interests within the set of those for which he can account, and this alternative explanatory resource is now used. This 
retrospective reference is warranted by utterance [9], and deployed in utterance [10]. Furthermore, the enrolment by the library of interests based on the category 'research' is described ambivalently in utterance [7] as 'control over what people are reading', which might undermine the legitimacy of this enrolment. As in the first excerpt, we might view this switch from technological determinism to an explanation based on social and economic interests as analagous to the SCOT approach, described above. Indeed, the financial interests are so effective an explanatory resource, and those based on 'research' are so undermined, that in utterance [11] the respondent is apparently able to contradict what was said in [6] regarding whether libraries lose. The candidate turn completion (Sacks, Schegloff and Jefferson 1974) at the end of [11] is followed by a unilateral change of topic to the next issue in the interview schedule. This move is not resisted by the interviewer, suggesting that the excerpt up to the end of utterance [11] represents what passed as an adequate answer to the interview question.

\section{Discussion: Indexical scholarly communication}

Scholarly communication or, at least, scholarly work was a category entitlement in the interviews. That is, the respondent that could construct himself as a member of a category 'researcher' had both an entitlement to speak of entailed interests, and an obligation to maintain the integrity of the category. Similarly, the category of 'researcher' served as an explanatory resource for both of the respondents who were not researchers, in that researchers' interests were a constituent of their accountability as category members. While these interests were a legitimate basis for a category such as 
'librarian', others were not. For example, the librarian respondent in the second excerpt described publishers' interests as economic as a way of excluding them from her set of accountable interests, and this limited her category entitlement. Perhaps as a result, she was unable to challenge the technological determinism of the interview question in anything like as effective a way as did both the researcher and the document supplier.

The distinctions made within the category of research did not overtly map onto a formal / informal division of scholarly communication. That is to say, in the excerpts analysed, such a division was not obviously used by the respondents in answering the question. Other distinctions were made, however, such as that between fieldwork and literature review (in the first excerpt) and that between commercial interests and those derived from the category of 'research' (in the second and third excerpts). These distinctions can be described as having worked as interpretative repertoires, or as sets of lexical and semantic resources available to make certain distinctions in certain ways. In discussing the deployment by academic psychologists of the empirical and contingent repertoires identified by Gilbert and Mulkay (1984), McKinlay and Potter (1987) note how this deployment is tempered in the interactional, public space of a conference (and, indeed, how such tempering can be seen to be a constituent of such a conference). That is, imputing social or psychological interests to researchers was problematic in a public arena where it could be seen as an accusation of unprofessional behaviour. Instead, vague terms like 'people' and 'some of us' were used as targets for such imputations. Similar structural constraints operated on the respondents in the excerpts analysed above, in that respondents were obliged to address their answers to the terms given in the 
interview question if interactional trouble were to be avoided. The consequent interest management issues are discussed below. The point here is that, in interactions around the answering of interview questions, scholarly activity, the work of the researcher, served as the basis for a category that was indexically deployed in interviews in a similar way to the deployment at a conference of the empirical and contingent repertoires. That is, for example, when the researcher excluded certain activities from this category (in an effort to answer the interview question), he then had to temper this exclusion by making it clear that it did not imply that they were less professional.

It is possible to argue that the interviews were examples of meta-communication, that is that they were communication about scholarly communication. Adopting this representational perspective of language use for the moment, the formal scholarly communication talked of by the librarian and the document supplier were aspects of researchers' work that constituted and legitimated a space that we might call the academic information chain. This was legitimated differently by the librarian, who used the artifacts of formal scholarly communication as the basis for her role (second excerpt, utterance [7]), and by the document supplier, who described such artifacts as illegitimate controls over researchers (third excerpt, utterance [7]). Answering a different interview question, the researcher in the first excerpt seems to equate formal scholarly communication with the information chain, as getting an overview of the literature (first excerpt, utterance [7]). Discourse analysis, however, focuses on the interactional rather than the representational functions of language use, so that the interviews themselves might be understood as informal scholarly communication, in the same way as was the 
conference studied by McKinlay and Potter (1987). Certainly, both interactants in each of the research interviews overwhelmingly and demonstrably oriented to it as a research interview, that is, as an interaction that contributed to research ${ }^{1}$. Doing scholarly communication in this sense involved a category of 'research' that was available to interactants as an explanatory resource only in certain ways. This category was indexical, that is, it was used relationally from the point in the interaction at which it was invoked. It defined those matters that were accountable while the interviewee spoke as a member, and those that were not. For example, the researcher in the first excerpt had to work up his membership of a new category to speak of literature review. This reflexively interactionist perspective is distinct from scholarly communication being either an information flow (Shannon and Weaver 1949) or a semiotic system (Barthes 1972), and is also the basis for understanding technology as a matter of interest management.

\section{Discussion: Technological determinism and interest management}

The three brief analyses offered above demonstrate how interview questions that offered technological determinism as an explanatory resource were addressed by a researcher, a librarian and a document supplier. The three criteria suggested above for the completion of adequate answers to interview questions were shown to reflect participants' orientations in the procudures by which answers were given. That is, respondents oriented to the business of claiming membership of a relevant category, maintaining the

\footnotetext{
${ }^{1}$ Reflexive concerns are obvious here, but the more esoteric of them are not explored. For example, the interviewer was also a researcher. Furthermore, the findings are being reported here in the form of formal
} 
integrity of this category, and offering accounts that would be accepted as answers within the interview interaction. The third criterion meant that all three respondents began their answers by adopting the technological determinism of the question. Two of them, the researcher and the document supplier, then switched to explanations rather like those offered by analysts working within the SCOT approach to technology studies, in that technology was taken out of the 'black box' (Bijker, 1995) and made subject to other interests. The other respondent, the librarian, did not do this.

Within the SCOT approach, technologies are flexible for a time, and are only fixed by the action of social interests. After that, technology will appear to be an adequate explanation for some phenomena, although it is always in principle susceptible to decomposition into the social and other interests that contributed to its crystallization in a particular form (Callon and Law 1989). This permeability between the social and the technical offers one way to understand the procedures apparent in the excerpts analysed above. Following Potter's (1996) equating of interests explanations with those based on interpretative repertoires, as discussed above, and drawing on Actor-Network Theory (Latour 1991), we might posit two repertoires of apparently determinist technology; automation and empowerment. Automation occurs when all the interests for which a category is accountable are crystallized into an artefact. This is a discursive act, since the set of interests for which a category is accountable is, as demonstrated in the excerpts above, subject to construction within particular interactions. Empowerment is automation viewed from the perspective of those whose interests were previously

scholarly communication. For the sake of both brevity and simplicity, neither of these matters is taken further. 
accounted for. For example, in the third excerpt analysed, the library is subject to automation in utterance [7] when the interests of the 'researcher', which were previously accounted for by the category 'librarian' are now crystallized into the 'database'. Thus, there is a type of explanation available to respondents that can appear to be technologically deterministic, but which is only so relative to the interaction at hand. Because they were essentially two sides of the same coin, use of one of the repertoires rendered the other expectable. For example, in the second excerpt analysed, the apparent inconsistency between utterances [14] and [15] is comprehensible by reference to the relative positions of automation and empowerment that the librarian and the researcher find themselves at that point in the interview.

The finding that the concept of technology as used by information professionals is made up of at least two discernible repertoires, and that the invocation of one makes the second expectable, is similar to Billig's (1996) arguments concerning what he calls 'commonsense'. Billig argues that the common-sense of many topics is made up of contrary 'common-places', between which a speaker can switch, using each to qualify the other so as to avoid interactional trouble or problematic inferences being drawn. For example, an ex-captain of the England cricket team (and qualified psychotherapist) is quoted as saying, "A captain must get the best out of his team by helping them play together without suppressing flair and uniqueness" (Brearley, 1985 p.13). Billig argues that common-sense is dialogically structured, so that in some way the first part of Brearley's statement makes the second part expectable. 
The interview excerpts analysed in this paper seem to have a similar structure with respect to the concept of technology. That is, they are dilemmatic (Billig, 1996), having technology as the agent of automation on the one hand and on the other as a tool empowering people. Respondents negotiated this dilemma with regard to their having an intra-discursive identity (interviewee) and an extra-discursive identity (for example, researcher), defending the category entitlement afforded by the latter in order to offer the accounts expected of the former. In this way, 'everyday explanations' (Heritage, 1984) of technology and scholarly communication are procedurally structured as reflexive social actions. That is, the twin repertoires of automation and empowerment were a member's resource; they were available and deployed to construct adequate answers to interview questions, answers that protected the category membership (and hence accountability) of the speaker.

The dilemma faced by the respondents was that of technological determinism. That is, the interviewer had in each case offered a question about the effects of technology of the kind that, as noted at the start of this paper, also frames much information science research in this area. Accounting for technology as an agent in this way seems to require an assessment of its empowering and automating effects and, if respondents or information science researchers are to maintain their entitlement as qualified and relevant givers of accounts, then the assessment should have technology empowering those identities. Note that this is an interactional constraint on those offering accounts (be they respondents or information science researchers) that stems from a characterisation of technology as determining. 
An alternative, as researchers in the SCOT tradition have demonstrated, is to reject the question as it is framed, and this is, as Billig (1996, p.254) notes, the classic response of the skilled rhetorician. However, replacing technology with social factors as determining or explaining whatever effects are of concern does not change the form of the argument and, as noted at the start of this paper, Woolgar (1981) has pointed out the dilemmas of this approach.

A second alternative is to make the form of argument the topic, and this is the approach adopted by discourse analysts. Recent work on technology has pointed to its metaphorical qualities. For example. McOmber (1999, p.149) notes that "with a concept as broad as technology, some degree of metaphorical or metonymic replacement or displacement seems a necessary prerequisite to any definition". On the related theme of information, Day (2000) offers a critique of the 'conduit metaphor' that has been so influential in information science. One objective of these writers is to open up concepts such as information technology to scrutiny and thereby to enable analyses of how they are used, both by the kinds of information professional who were 'respondents' in this paper, and by information science researchers themselves. From this perspective, the answer to the question 'in whose interests is information technology?' may turn out to be both more difficult and of wider relevance than previously thought. Discourse analysis offers one practical means whereby the question can be so addressed. 


\section{References}

Antaki, C. and Horowitz, A. (2000) Using identity ascription to disqualify a rival version of events as 'interested'. Research on Language and Social Interaction, 33(2), 155-177.

Antaki, C. and Wetherell, M. (1999) Show concessions. Discourse Studies. 1(1), 7-27.

Ashmore, M. (1989) The reflexive thesis: wrighting sociology of scientific knowledge. Chicago: University of Chicago Press.

Barthes, R. (1972) Mythologies. London: Jonathan Cape Ltd.

Bijker, W. (1995) Of bicycles, bakelites and bulbs: toward a theory of sociotechnical change. Cambridge, MA: MIT Press.

Billig, M. (1996) Arguing and thinking: a rhetorical approach to social psychology, 2nd edition. Cambridge, UK: Cambridge University Press.

Borgman, C.L. (2000) Digital libraries and the continuum of scholarly communication. Journal of Documentation, 56(4), 412-430.

Brearley, M. (1985) The art of captaincy. London: Hodder and Stoughton. 
Budd, J.M. and Raber, D. (1996) Discourse analysis: method and application in the study of information. Information Processing and Management, 32(2), 217-226.

Callon, M. and Law, J. (1989) On the construction of sociotechnical networks: content and context revisited. Knowledge and Society, 8, 57-83.

Collins, H.M. (1981) Stages in the empirical programme of relativism. Social Studies of Science, 11, 3-10.

Collins, H.M. (1998) The meaning of data: open and closed evidential cultures in the search for gravitational waves. American Journal of Sociology, 104(7), 293-338.

Costa, S. and Meadows, J. (2000) The impact of computer usage on scholarly communication among social scientists. Journal of Information Science, 26(4), 255-262.

Crabtree, A. et al (2000) Ethnomethodologically informed ethnography and information system design. Journal of the American Society for Information Science, 51(7), 666-682.

Davenport, E. (1993) The author in the digital environment. In A.M. Cunningham and W. Wicks (Eds.), Changing roles on information distribution. Philadelphia, PA: National Federation of Abstracting and Information Services. 
Day, D. et al (1993) Agents for electronic document supply: who are the likely players? Aslib Proceedings, 45(7/8), 189-199.

Day, R. (2000) The 'conduit metaphor' and the nature and politics of information studies. Journal of the American Society for Information Science, 51(9), 805-811.

Doolin, B. (1998) Information technology as disciplinary technology: being critical in interpretive research on information systems. Journal of Information Technology, 13, 301-311.

Edwards, D. (1997) Discourse and cognition. London: Sage.

Edwards, D., Ashmore, M. and Potter, J. (1996) Death and furniture: the rhetoric, politics and theology of bottom line arguments against relativism. History of the Human Sciences, 8(2), 25-49.

Ekman, R. \& Quandt, R.E. (Eds.). (1999) Technology and scholarly communication. Berkeley: University of California Press.

Foucault, M. (1972) The archaeology of knowledge and the discourse on language. New York: Pantheon Books. 
Frohmann, B. (1994) Discourse analysis as a research method in library and information science. Library and Information Science Research, 16, 199-138.

Garfinkel, H. (1967) Studies in ethnomethodology. Englewood Cliffs, New Jersey: Prentice Hall.

Gilbert, G.N. and Mulkay, M. (1984) Opening Pandora's box: a sociological analysis of scientists' discourse. Cambridge, UK: Cambridge University Press.

Grint, K. and Woolgar, S. (1997) The machine at work: technology, work and organization. Cambridge, UK: Polity Press.

Heidegger, M. (1977) The question concerning technology. In D.F. Krell (Ed.), Basic writings. London: Routledge and Kegan Paul.

Heritage, J.C. (1984) Garfinkel and ethnomethodology. Cambridge, UK: Polity Press.

Hughes, T.P. (1983) Networks of power: electrification of western society, 1880-1930. Baltimore: John Hopkins University Press.

Jacobs, N. et al (2000) Planning document access: options and opportunities. London: Bowker-Saur. 
Kelland, J.L and Young, A.P. Citation patterns and library use. In: Kent, A. ed. Encyclopaedia of Library and Information Science. Volume 61, 1998. New York: Marcel Dekker.

Kerslake, E. and O'Brien, A. (1999) Storm Center: a discursive approach to constructions of library workers. Library Management, 20(8), 439-446.

Latour, B. (1991) Technology is society made durable. pp. 103-131 In: A sociology of monsters: Essays on power, technology and domination. (Law, J., eds.) Routledge, London.

Leudar, I. and Antaki, C. (1996) Discourse participation, reported speech and research practices in social psychology. Theory and Psychology, 6(1), 5-29.

McKinlay, A. and Potter, J. (1987) Model discourse: interpretative repertoires in scientists' conference talk. Social Studies of Science, 17, 443-463.

McKnight, C. et al (2000) Librarians in the delivery of journals: roles revisited. Journal of Librarianship and Information Science, 32(3), 117-134.

McOmber, J.B. (1999) Technological autonomy and three definitions of technology. Journal of Communication, 49(3), 137-153. 
MacRoberts, M.H. and MacRoberts, B.R. Problems of citation analysis. Scientometrics, 36(3), 1996, 435-444.

Parker, I. (1992) Discourse dynamics: critical analysis for social and individual psychology. London: Routledge.

Pinch, T.P. and Bijker, W.E. (1987) The social construction of facts and artefacts: or How the sociology of science and the sociology of technology might benefit each other. In W.E. Bijker, T.P. Hughes and T. Pinch (Eds.), The social construction of technological systems. Cambridge, MA: MIT Press.

Pollner, M. (forthcoming) Inside the bubble? Community, meaning and deep play at the intersection of Wall Street and cyberspace. In S. Woolgar (Ed), Virtual society. Oxford: Oxford University Press.

Potter, J. (1996) Representing reality. London: Sage.

Potter, J. and Wetherell, M. (1987) Discourse and social psychology. London: Sage.

Psathas, G. (1995) Conversation analysis: the study of talk-in-interaction. London: Sage.

Psathas, G and Anderson, T. (1990) The 'practices' of transcription in conversation analysis. Semiotica, 78(1/2), 75-99. 
Sacks, H. (1992) Lectures on conversation. G. Jefferson (Ed.) Oxford: Blackwell.

Sacks, H., Schegloff, E. and Jefferson, G. (1974) A simplest systematics for the organization of turn-taking for conversation. Language, 50(4), 696-735.

Schegloff, E.A. (1992) Repair after next turn: the last structurally provided defense of intersubjectivity in conversation. American Journal of Sociology, 97(5), 1295-1345.

Shannon, C. and Weaver, W. (1949) The mathematical theory of communication. Illinois: University of Illinois Press.

Tuominen, K. (1997) User-centred discourse: an analysis of the subject positions of the user and the librarian. Library Quarterly, 67(4), 350-371.

Warner, J. (2000) What should we understand by information technology (and some hints at other issues)? Aslib Proceedings, 52(9), 350-370.

Wetherell, M. (1998) Positioning and interpretative repertoires: conversation analysis and post-structuralism in dialogue. Discourse and Society, 9(3), 387-412.

Williams, R. and Edge, D. (1992) The social shaping of technology: research concepts and findings in Great Britain. In M. Dierkes and U. Hoffmann (Eds.), New technology at 
the outset: social forces in the shaping of technological innovations. Frankfurt / Main: Campus Verlag.

Williams, R. and Edge, D. (1996) The social shaping of technology. In W.H. Dutton (Ed.), Information and communication technologies: visions and realities. Oxford: Oxford University Press.

Woolgar, S. (1981) Interests and explanation in the social study of science. Social Studies of Science, 11, 365-394.

Woolgar, S. (Ed). (1988) Knowledge and Reflexivity: new frontiers in the sociology of knowledge. London: Sage.

Woolgar, S. (1991) Beyond the citation debate: towards a sociology of measurement technologies and their use in science policy. Science and Public Policy, 18(5), 319-326. 


\section{Appendix - the interview schedules}

The following represent the schedules used in the interviews conducted as a part of the UK eLib FIDDO Project. The excerpts analysed in this paper are taken from verbatim transcripts from these interviews. There are two schedules:

- evaluation interviews with academic researchers;

- interviews with information professionals.

In all cases, the author was the interviewer.

The full toolkit is published in:

Jacobs et al (2000) Planning document access: options and opportunities. London:

Bowker-Saur 


\section{Interview schedule: evaluation interview with academic researchers}

I'd like you to imagine the times when you used SYSTEM to (search for and) get hold of literature that you need for this research work.

E.1. What were your general impressions of SYSTEM?

[Aim of question is to get user's impressions of the system as they are structured by the user - that is, relatively unprompted by the researcher]

E.2. Did SYSTEM cover the kinds of subjects are you wanted documents in?

E.3. Did SYSTEM cover these subjects in enough depth (i.e. did searches bring up enough hits)?

E.4. Did SYSTEM cover these subjects appropriately (i.e. were the hits from quality journals, etc) [Aim of these questions is to assess the perceived coverage of the system, and its appropriateness to the user's needs. The coverage reported here may or may not be related to the 'actual' coverage]

E.5. If you could have access to any document via SYSTEM, what problems would still remain with it? 
[Aim of question is to assess user's views of aspects of the system other than its coverage]

E.6. Would / will you regularly use SYSTEM?

If $\mathrm{N}$ - why not? Which alternatives are better? And in what way are they better?

If Y - what would / will you do less of to make time to use SYSTEM?

[Aim of question is to get user to compare the system with other methods of getting hold of documents, and so to tell the researcher which criteria are important to the user in such comparisons]

E.7. Were there particular issues with receiving documents in electronic format? [Aim of question is to get user's views on their experience of using electronic format, as compared (perhaps) with their general views on the subject as expressed in the initial interview]

E.8. Was is quicker using SYSTEM than it would have been to use the traditional way of doing things? Why? Which part of the process was quicker / better (or slower / worse?)

[Aim of question is to assess whether time was an important issue in using the system]

E.9. What were the best and worst aspects of using SYSTEM for document access? [Aim of question is to reassess user's general reaction to the system] 
E.10. Did you feel in control of your access to documents using SYSTEM? [Aim of question is to assess user perceptions of the extent to which they believed their work was constrained by the system used]

E.11. How easily did SYSTEM fit into your overall way of doing things? [Aim of question is to assess perceived compatability between system used and the tasks it was supporting]

E.12. Did you have to ask for help when first obtaining documents using SYSTEM? Was that help forthcoming? Was it adequate, effective and easy to understand? [Aim of question is to assess both perceived difficulty of accessing documents and system / service features apparent to users to help them]

E.13. What problems do you think a new user might have when using SYSTEM for the first time?

[Aim of question is to assess the degree to which the system was perceived as easy to learn]

E.14. Do you think having access to SYSTEM has / would have an effect on the quantity or quality of your research?

[Aim of question is to assess perceived potential of system in relation to constraints of current options, as identified in the initial interview] 
Jacobs 45

E.15. Were there any technical issues using SYSTEM?

[Aim of question is to assess user-perceived technical reliability of the system] 


\section{Interview schedule: interview with information professionals}

The aim for the interviews was to gain an understanding of the way members of the academic information chain viewed the present and the future of document access, what the major issues were for them, and how they saw themselves dealing with those issues. It is sometimes difficult to talk about what are often very practical issues in these abstract ways, and so a set of four hypothetical scenarios was developed on which to base the interviews. These described different ways in which end-users could obtain documents, with different potential roles for the library and others in the information chain. The descriptions of the scenarios were left fairly vague, so that interviewees would be able to focus on the significant unresolved issues in them. The four scenarios were:

\section{Scenario 1:}

Users search a new subject-based full-text database on the Web, viewing those documents in which they are interested, with an option to print them out. There are options to view / print documents in text-only or in PDF format. All full-text is copyright-cleared, and the database provider charges a flat-rate access fee, depending on how many simultaneous accesses are allowed. The average delay between a user's decision to have a (printed) document and actually having it is 10 mins. 


\section{Scenario 2:}

Users search a known and familiar subject database on the Web, ordering photocopies of those documents in which they are interested by clicking on the appropriate button. The documents are then sent by a supplier directly to the users' via the postal service. The documents are available under the 'fair dealing' provisions of UK copyright law. There is a subscription charge to the database, plus a charge for each document ordered, depending on the supplier. The library can set the system to try certain suppliers for particular journal titles or publishers. The average delay between a user's decision to have a (printed) document and actually having it is three days.

\section{Scenario 3:}

Users input their requests for documents to the university library via a Web form, or via email. The library decides on the best supplier for each article and makes the order. The document is delivered to the library, checked in and forwarded to the users via the internal mail. There is a charge for each document. The average delay between a user's decision to have a (printed) document and actually having it is five days.

\section{Scenario 4:}

Users send their requests for documents via email to a document supplier. The documents are supplied in PDF format as email attachments within a couple of days if the item is in the supplier's collection, or one - two weeks if not. There is a charge for each document, 
consisting of a flat rate delivery charge plus a variable copyright charge depending on the publisher of the document. The documents are therefore copyright-cleared.

A series of questions were asked for each hypothetical scenario, designed to elicit discussion of the practicalities and potentials of each scenario:

1. Who would you expect to pay? How?

2. Who regulates access?

3. What university / external infrastructure is necessary?

4. What is the role of the library?

5. Compared to journals-on-the-shelf, who wins and who loses?

(for example; publishers, suppliers, libraries, researchers, students, university administration, no-one) 